\title{
Using Rational Cloze for Diagnostic Testing in L1 and L2 Reading
}

Margaret MacLean

\footnotetext{
Although both first and second language reading have been frequently explored, much of the research has tended to be product oriented and comparative in nature. That is, researchers have tended to focus on quantitative differences in reading comprehension test scores between groups of native and non-native speakers. Very few studies have examined how readers understand text in both their first and second languages. This paper presents results from a case study of a bilingual reader (French L1/English
}

\begin{abstract}
L2) who read both easy and hard texts in her first and second language. Rational cloze and introspection tasks were used to examine quantitative and qualitative differences in comprehension across languages. Results indicated that there were differences in the extent to which this reader successfully manipulated meaning especially at the whole text level. Implications of the rational cloze procedure for diagnostic testing and teaching are discussed.
\end{abstract}

Reading comprehension is a topic of considerable interest to researchers concerned about how readers understand text. Although the area has been frequently explored, its complexity has created difficulties for those trying to develop measures which provide insights into the interactive nature of the processes underlying text comprehension.

Two assessment procedures which have been frequently used by first and second language reading researchers for examining how readers understand text are rational cloze (Bachman, 1982; Bridge \& Winograd, 1982; Clarke, 1981; Levenston, Nir, \& Blum-Kulka, 1982) and mentalistic approaches such as protocol analysis, retrospection, or introspection (Cohen, 1982; Cohen \& Hosenfeld, 1981; Hare \& Pulliam, 1980; Olshavsky, 1976-77). These procedures offer insights into text processing while at the same time maintaining the dynamic and interactive nature of the reading act without dissecting it into isolated skills for separate examination.

Using the rational cloze procedure, it is possible to examine to what extent a reader constructs and manipulates meaning across text by selectively deleting words which require a reader to attend to different levels of text information (e.g., clause, sentence, or whole text levels) and by scoring responses in terms of their syntactic and semantic acceptability at local and/or global text levels. This differential sampling and scoring of comprehension would appear especially useful for diagnostic purposes where one 
is interested in the extent to which a reader is sensitive to different levels of text information. Kintsch and Yarborough (1982) suggest that "one may comprehend words but not the meaning of a sentence, or one can understand sentences but still be confused about the overall organization of a text" (p. 828). With its selective deletions and differential scoring of responses, rational cloze would appear to offer opportunities to examine to what extent a reader is able to use different levels of textual and extratextual information to formulate and re-formulate meaning while reading.

Mentalistic approaches also offer insights into how a reader makes sense of a text. Strang (1962) states that the "dynamic process by which individuals of different ages, mental abilities, interests, and backgrounds comprehend and interpret what they read...can be obtained most directly from introspection-retrospection accounts" (p. 188-189). Cohen (1982) suggests that mentalistic procedures are especially appropriate for examining the strategies a reader uses to obtain meaning from text and for obtaining information about a reader's perspectives regarding language difficulties with a text. For diagnostic purposes, this information would appear to be most useful for understanding how a reader makes sense of text.

Although both rational cloze and introspection have been used separately to examine how first and second language readers understand text, they tend not to have been used together. However, first language (L1) research with junior high good and poor readers (Bridge \& Winograd, 1982; Rains, 1981) and mature fluent readers (MacLean, 1982) has indicated that by combining rational cloze with introspection one can examine not only how well a reader creates and manipulates meaning while reading, but also what strategies are used to accomplish this.

The purpose of this paper is to examine how rational cloze and introspection can be used together as a diagnostic measure to gain insights into first and second language reading. Data are presented from a case study of a bilingual reader, Anna, to illustrate the kinds of diagnostic information which are available from these procedures.

\section{METHODOLOGY}

Anna, a 20 year old advanced level English second language learner whose first language is French, volunteered to participate in this case study. In response to questions regarding her educational background, Anna indicated that she completed all her elementary and secondary level education in French schools. She has studied English for the past six years 
and is now enrolled in her second year at an English junior college where all her courses except one are conducted in English.

A survey of Anna's leisure and school related reading revealed that she regularly reads French newspapers (approximately 15-30 minutes three times per week), English and French magazines (approximately 30 minutes once per week), and both English and French books (approximately 30-60 minutes each day). Commenting on her book reading, Anna stated that she tends to do more school related reading in English and more leisure related reading in French.

\section{Procedures}

Rational cloze differs from random cloze as deletions are selective rather than random, and non-exact as well as exact replacements are scored. The rational cloze procedure developed for this case study was similar to other rational cloze measures (Clarke, 1981; Levenston et al, 1982) in that similar types of words were deleted: content words (nouns, verbs, adverbs, adjectives), words with specific referents in prior or subsequent text, and discourse markers. However, this rational cloze measure differed from other measures as deletions were made at two levels of text: within sentence (a reader is able to use information within the sentence to complete the blank) and between sentences (a reader needs to use information beyond the sentence to complete the blank). Several researchers (Cziko, 1978; Douglas, 1981; Hauptman, 1979; Hosenfeld, 1977) have suggested that non-native speakers may not be able to use contextual constraints beyond the sentence level as effectively as native speakers. By including both within and between sentence deletions, this rational cloze measure was able to examine how effectively Anna used different levels of text information during $L 1$ and $L 2$ reading.

Rational cloze responses were scored in terms of exact and acceptable replacements. The acceptable replacements were scored at the sentence level (the response produced a sentence which was grammatically acceptable and which made sense) and at the whole text level (the response was grammatically acceptable and did not significantly change or contradict global text meaning). By examining the extent to which acceptable responses were congruent with local and global text meaning, one can gain insights into how and how well a reader understands text.

After completing each text, Anna was asked to explain why she generated selected responses. Probes such as, "What helped you to decide to put in ?" or "What gave you the idea to put in ?" were used to elicit her explanations. These introspections were recorded and used as a source of anecdotal information regarding the strategies that Anna used to understand text. 


\section{Materials}

Anna read a total of four expository texts: two in English and two in French. Each text was approximately 320 words long and contained 16 deletions. These texts represented two levels of difficulty as assessed by readability formulae: easy (which corresponded to grade $9 / 10$ level of difficulty) and hard (which corresponded to college level readability). Equivalence of text difficulty across languages was confirmed by preliminary testing with native speakers of both English and French who were asked to complete random cloze passages prepared on the texts. Results indicated that there were significant differences in the random cloze scores on the easy/hard texts in both English and French, but no significant differences in scores within the easy texts across languages or within the hard texts across languages.

Anna read the four texts (easy English, hard English, easy French, hard French) in two sessions. A variety of texts were included in this assessment in order to determine to what extent Anna's reading changed across texts within a language (easy versus hard English texts; easy versus hard French texts) and across languages within texts (English versus French easy texts; English versus French hard texts).

\section{RESULTS}

Figure 1 illustrates Anna's rational cloze performance across all four texts. Examination of these results indicates that Anna's acceptable

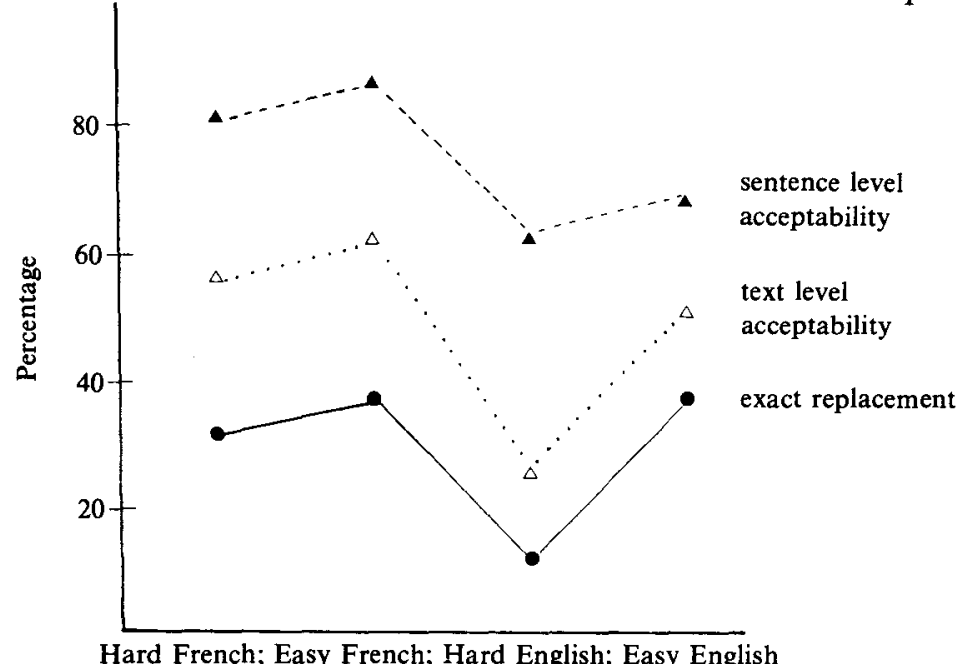

Figure 1. Rational Cloze responses scored for exact replacement, sentence level acceptability, and text level acceptability 
response scores (both text and sentence level) tended to be higher than her exact replacement scores. Furthermore, her sentence level acceptability scores tended to be higher across all texts than either her text level acceptability scores or her exact replacement scores.

Comparison of results on the easy versus hard French texts shows that the scores tended to be similar within each scoring method, with scores slightly higher on the easy text than on the hard text. For the English texts however, only the sentence level acceptability scores were similar. On both the text level acceptability and exact replacement scoring, the hard English text scores were substantially lower than the easy English text scores.

Comparison of results across languages within text types (easy English versus easy French; hard English versus hard French) shows that on the easy passages, text acceptability and exact replacement scores tended to be similar. However, sentence acceptability scores tended to be lower on the easy English text. On the hard texts, all scores were clearly lower on the hard English text. These results suggest Anna had more difficulty generating responses which were exact or acceptable replacements for the hard English text than she did for the hard French text or for either of the easy texts.

In an attempt to gain further insights into the extent to which Anna attended to different levels of information across texts, the acceptable scores were re-examined in terms of the proportion of between and within sentence deletions successfully completed. This re-examination was limited to acceptable responses as for diagnostic purposes these responses allow more insights into the extent to which a reader attempts to make sense of a text than do exact replacements. These results are presented in Figures 2 and 3.

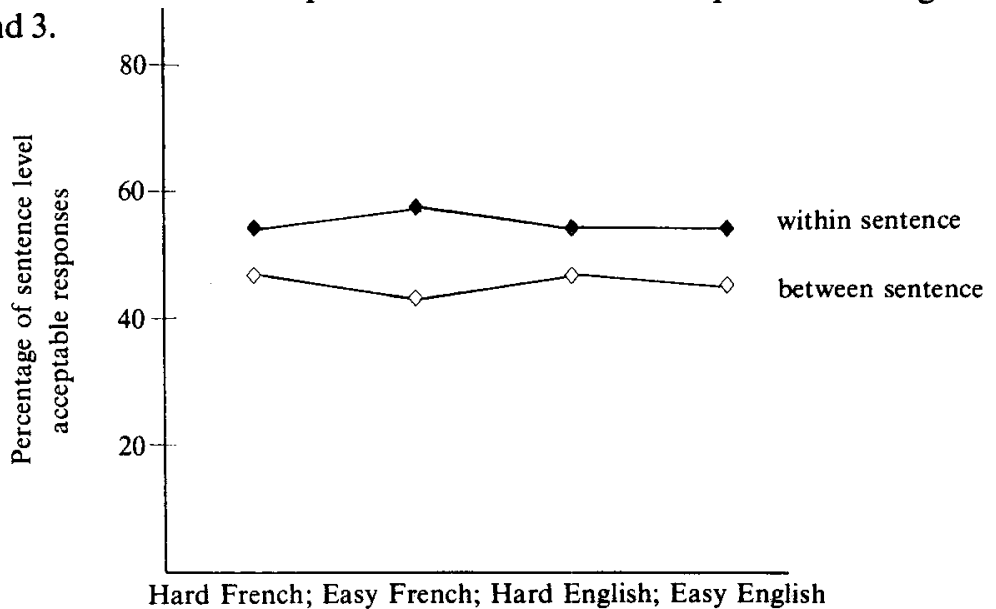

Figure 2. Rational Cloze responses acceptable at the sentence level: Distribution of between sentence and within sentence deletions 


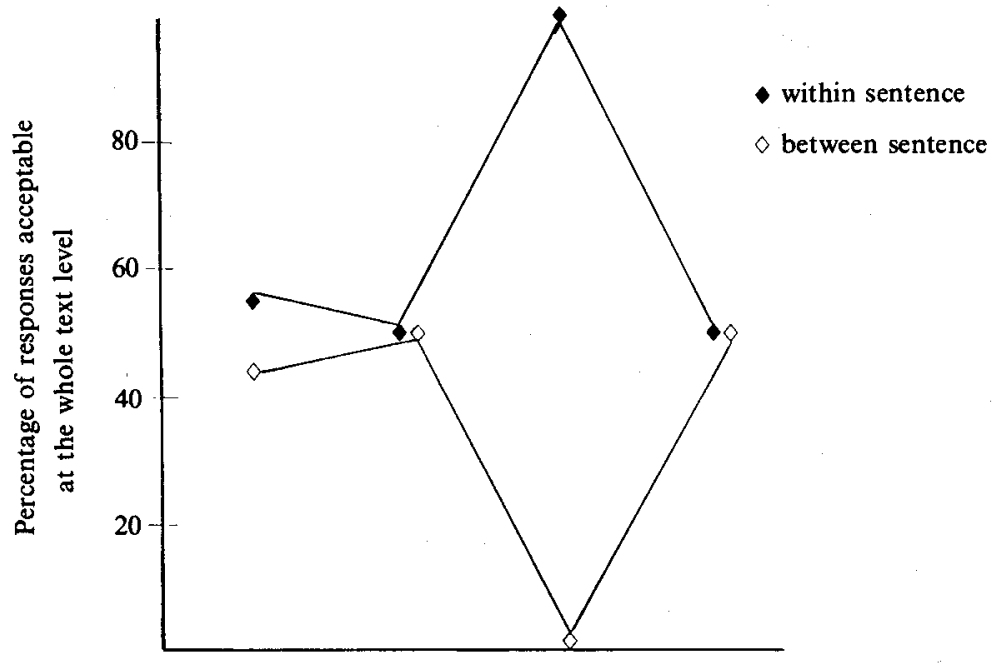

Hard French; Easy French; Hard English; Easy English

Figure 3. Rational Cloze responses acceptable at the whole text level: Distribution of between sentence and within sentence deletions

As Figure 2 indicates, the patterns of between and within sentence deletions which were acceptable in terms of sentence level meaning is similar across all texts. These results suggest that in general, Anna was able to generate responses which were acceptable in terms of sentence level meaning equally well for between sentences and within sentence deletions on easy and hard texts in both English and French.

Figure 3 shows the distribution of between and within sentence deletions which were acceptable in terms of whole text acceptability. Results indicate that the pattern of results was similar on all texts except on the hard English text. Examination of Anna's responses on this text which were acceptable at the text level indicated that all were within sentence deletions. None of Anna's responses for the between sentence deletions were acceptable in terms of whole text acceptability. This pattern of results for between and within sentence deletions is clearly different from the other texts where between sentence and within sentence results were similar.

Figure 1 suggests that there were differences across languages and across texts in the extent to which Anna was able to construct and manipulate meaning successfully across various levels of text. These differences were most apparent on the L2 (English) texts. It seems that Anna 
had more difficulties generating sentence and text level acceptable responses on the English texts than she did on the French texts. This difficulty was especially evident on the hard English text where Anna's whole text level acceptability score was clearly lower than on any other text. Figure 3 indicated that Anna's difficulties with this text were evident on between sentence deletions.

Further evidence that Anna had problems with between sentence deletions on the hard English text emerged when she was asked to explain why she generated the responses she did for several blanks on this text. For example, she was asked to explain why she supplied the word national in the sentence "In Sweden, the budget is now close to $\$ 2$ billion". Anna explained

\section{Well, budget concerns the country and another word for country is national... so national budget.}

While this response is acceptable at the sentence level, it is not acceptable in terms of whole text meaning as it ignores previous information in the paragraph which discusses the increase in health budgets.

Anna also had problems with the sentence "Since that time has not increased significantly for males and has increased only slightly for females". Discussing her response, diseases, Anna said

I think that diseases for males and females are not the same. It says since that time diseases has not increased significantly for males and only slightly for females. Diseases is the only thing that fits there.

While Anna appears to be trying to bring in personal knowledge of the topic ("I think"), she is ignoring subject-verb agreement as well as previous and subsequent information in the paragraph which clearly refers to the topic of longevity.

Anna also tried to interpret the sentence "__ increasing the budget doesn't inevitably equal better health," in terms of her prior knowledge. She explained

I don't really know what to put there...Something to do with research as it says increasing the budget doesn't necessarily increase health. Well, research would mean better health. And it would increase the budget too as it costs lots of money.

In another example from this text, Anna again tried to relate text information to her prior knowledge of the topic and to expand on text information. For the sentence, "One cannot avoid the thought that our modern way of life could be an important factor and that the main determinants of are now more cultural than medical," 
Anna explained her response (diseases) by saying

\begin{abstract}
Well, the fact that modern way of life is an important factor...It says here. It's talking about what determines diseases and I'd say it was way of life. The way people live affects their diseases...especially in underdeveloped countries where their way of life isn't very good...Umm...I don't know why they put cultural there. It doesn't make sense to me.
\end{abstract}

These examples suggest that Anna is trying to make sense of the hard English text. She is trying to monitor her comprehension ("It doesn't make sense to me"; "I don't know what to put here") and to apply a variety of strategies, such as rereading parts of the sentence, grasping at key words, and elaborating on text information to help her complete the rational cloze deletions. However, her explanation for her responses on the hard English text indicate that she frequently tended to ignore information beyond the sentence. She appears not to be checking local or global information as effectively as she did on the other texts.

Examination of her introspections on the other texts indicates more careful monitoring of local and global information. For example, she explained a response for a blank on the easy French text in this way:

I put in agées because the previous word told me that it had to have something to do with people. And the next sentence says vieux ...So it's about old people. We usually say personnes âgées ... So that's why.

Further evidence of her facility in using between sentence information and personal knowledge of the topic is evident in this explanation of a response for the hard French text

I said bas âge because I think mothers have problems with the young children and not the old ones. And then it says moins de 8 ans, so bas âge...

Another example which illustrates how Anna monitors text comprehension is available from her explanation of a response on the easy English text.

I used the word violence here because the previous part told me I had to choose the word what made sense in the context. Up there [She pointed to previous paragraph] it says the increase in violence and talks about how there is more violence in schools.

\title{
DISCUSSION
}

Results of this case study indicate that for the most part, Anna was able to manipulate meaning across various levels of text and to apply a 
variety of strategies to help her understand text. Results from the rational cloze indicate that Anna had more difficulty generating responses which are acceptable at the whole text level than at the sentence level. This result is not unexpected as constraints on meaning are more restrictive at the whole text level than at the sentence level. Results also indicated that this difficulty was most apparent on the hard English text. This difficulty does not appear to be the result of specific vocabulary or syntactic problems as Anna stated that she had no problems understanding the text.

Other researchers (Favreau \& Segalowitz, 1982; Favreau, Komoda, \& Segalowitz, 1980) have found that highly skilled bilingual readers may have problems in second language reading which are not necessarily due to inadequate knowledge of syntax or vocabulary. These researchers found that some fluent bilingual readers tend to read more slowly in their second language than in their first language. They suggest that this slower speed may be due in part to inefficient use of orthographic, syntactic, and semantic redundancies in the second language or may be related to more general second language processing factors.

Results of this study did not indicate that Anna read the second language passages more slowly than the first language passages. In fact, results revealed that she completed all passages at approximately the same speed. That is, she exhibited minimal flexibility in her reading rate across the passages. It is possible that the rational cloze task slowed down her typical reading rate. Perhaps if she had read unmutilated texts, her reading rates would have exhibited more diversity across easy/hard passages in English/French. Further diagnostic testing/ teaching sessions with Anna would be needed to investigate her apparent lack of flexibility in reading speed.

Another factor which may have contributed to Anna's poorer performance on the hard English text is the fact that her knowledge of this topic was less well-developed than for the other topics. Anna indicated that this text contained "new information about health and things" for her. Several researchers (Carrell \& Eisterhold, 1983; Johnston, 1982) have suggested that lack of appropriate background can significantly restrict a reader's efforts to understand text.

One also needs to remember that Anna has studied English for only the past six years, and although she reads regularly in English, most of her leisure reading is in French. One should not necessarily assume that because Anna is a fluent bilingual her reading would be equally proficient across languages or across various levels of text difficulty. Results of this case study, however, did indicate that it is important to include a variety of texts when assessing reading in order to determine under what 
conditions a reader's first and second language reading is most similar and where reading strategies differ.

The introspection data provide other insights into the reasons for Anna's differential performance across English/French easy/hard texts. These data suggest that although Anna appears to know a variety of strategies, she was unable to apply them successfully to help her monitor her comprehension on the hard English text. It seems that Anna focussed more on within sentence information than on between sentence information while completing the between sentence deletions.

Further practice with easy/hard texts in English and French using similar rational cloze plus discussion tasks would appear useful to help Anna focus on the interactive nature of reading. Rational cloze tasks with deliberate omissions of single words or phrases which required Anna to focus on different aspects of between-sentence or extra-textual information would appear useful for her. Discussion (introspection) activities which require readers to justify and defend their responses for rational cloze would also be helpful for her as they would help her to identify a variety of strategies which are effective for monitoring whole text level comprehension. It is important to include a variety of texts for these activities in order to help her realize how strategy use changes depending on one's purpose for reading, prior knowledge of text, complexity of text, goals, and/or interest.

Results of this case study suggest that rational cloze and introspection are useful for helping us understand how a reader comprehends $L 1$ and L2 text. As well, they appear to offer potential as diagnostic teaching tools which will help readers to focus on the interactive and creative nature of reading. Admittedly any diagnostic teaching and testing program should include other reading tasks in addition to rational cloze and introspection. However, these activities would appear to encourage a reader to become more active and flexible as $\mathrm{s} / \mathrm{he}$ constructs and manipulates meaning across multiple levels of text during L1 and L2 reading.

\section{REFERENCES}

Bachman, L. (1982). The trait structure of cloze test scores. TESOL Quarterly, 16(1), 61-70.

Bridge, C. \& Winograd, P. (1982). Readers' awareness of cohesive relationships during cloze comprehension. Journal of Reading Behavior, 14(3), 299-312.

Carrell, P. \& Eisterhold, J. (1983). Schema theory: ESL reading pedagogy. TESOL Quarterly, 17(4), 552-573.

Clarke, M. (1981). Reading in Spanish and English: Evidence from adult ESL students. In S. Hudelson (Ed.), Learning to read in different languages. Arlington, VA: Center for Applied Linguistics.

Cohen, A.(1982, August). Use of mentalistic measures in determining LSP reading 
problems. Paper presented at the International Symposium on LSP, Eindhoven, Netherlands.

Cohen, A. \& Hosenfeld, C. (1981). Some uses of mentalistic data in second language research. Language Learning, 31(2), 285-313.

Cziko, G. (1978). Differences in first and second language reading: The use of syntactic, semantic, and discourse constraints. Canadian Modern Language Review, 34(3), 473-489.

Douglas, D. (1981). An exploratory study of bilingual reading proficiency. In S. Hudelson (Ed.), Learning to read in different languages. Washington, DC:Center for Applied Linguistics.

Favreau, M., Komoda, M. \& Segalowitz, N. (1980). Second language reading: Implications of the word superiority effect in skilled bilinguals. Canadian Journal of Psychology, 34, 370-380.

Favreau, M. \& Segalowitz, N. (1982). Second language reading in fluent bilinguals. Applied Psycholinguistics, 3, 329-341.

Hare, V. \& Pulliam, C. (1980). College students' metacognitive awareness of reading behaviors. In M. Kamil \& A. Moe (Eds.), Perspectives in reading research and instruction. Washington, DC: National Reading Conference.

Hauptman, P. (1981). A comparison of first and second language reading strategies. ITL Review of Applied Linguistics, 51, 37-57.

Hosenfeld, C. (1977). A preliminary investigation of the reading strategies of successful and non-successful second language learners. System, 5, 110-123.

Johnston, P. (1982). Effects on reading comprehension of building background knowledge. TESOL Quarterly, 16,(4), 503-516.

Kintsch, W. \& Yarborough, J. (1982). Role of rhetorical structures in text comprehension. Journal of Educational Psychology, 74(6), 828-834.

Levenston, E., Nir, R., \& Blum-Kulka, S. (1982). Discourse analysis and the testing of reading comprehension by cloze techniques. Paper presented at the International Symposium on LSP, Eindhoven, Netherlands, (ED 224336).

MacLean, M. (1982). Reading processes of skilled older adult readers. (Doctoral dissertation, McGill University 1982). Dissertation Abstracts International, 43(4), 1123A.

Rains, M. (1981). Divergent-Cloze: A method for examining the reading process. Unpublished Master's thesis, McGill University.

Olshavsky, J. (1976-77). Reading as problem solving: An investigation of strategies. Reading Research Quarterly, 12, 654-674.

Strang, R. (1961). Reactions to research in reading. Educational Forum, 26, $187-$ 192.

\section{THE AUTHOR}

Margaret MacLean is a post-doctoral research fellow at the Université de Montréal. Her area of research interest is socio-and psycholinguistic aspects of second language literacy acquisition and development. She has been involved in teaching language and literacy at the university level for the past several years. Previous to that she taught at the elementary and high school levels in Canada and England. This paper was completed when the author was a post-doctoral fellow at Université de Montréal. 
